\title{
THE EFFECTS OF FATIGUE ON DRIVER PERFORMANCE FOR SINGLE AND TEAM LONG-HAUL TRUCK DRIVERS
}

\author{
Sheila G. Klauer \\ Thomas A. Dingus \\ Vicki L. Neale \\ Virginia Tech Transportation Institute \\ Virginia Tech \\ Blacksburg, Virginia, USA \\ E-Mail: charlie@vtti.vt.edu \\ Robert J. Carroll \\ Federal Motor Carrier Safety Administration \\ Washington, DC, USA
}

\begin{abstract}
Summary: Driver fatigue is an important safety issue for long-haul truck drivers. To provide an efficient means of obtaining sleep, long-haul truck drivers often use tractors equipped with sleeper berth units. Depending on the type of cargo and distances traveled, long-haul truck drivers either drive in teams or alone as single drivers. Team drivers, therefore, typically sleep in a moving truck whereas single drivers sleep in a stationary truck. It has been hypothesized that sleeping in a moving truck could adversely affect the sleep quality and, therefore, the alertness level of team drivers. A naturalistic data collection system was developed and installed in two Class 8 heavy trucks. This trigger-based system consisted of vehicle sensors and cameras that allowed the experimenters to obtain the driving performance and driver alertness data for analysis of fatigue. Fatigue was measured using both objective and subjective measures that were recorded before and after sleep and while driving. Fatigue and driving performance were compared for single versus team drivers to determine which driver type acquired the greatest sleep deficit during a trip. Results suggest that single drivers were more frequently involved in critical incidents while exhibiting extreme drowsiness than were team drivers by a factor of 4 to 1 . These results will be discussed in relation to the general safety of single versus team trucking operations.
\end{abstract}

\section{INTRODUCTION}

Fatigue in long-haul trucking continues to be a concern for the trucking industry and for regulating agencies (NTSB report, 1995). Many research studies cite driver fatigue as a major factor in highway collisions involving heavy vehicles (Pack, Pack, Rodgman, Cucchiara, Dinges, \& Schwab, 1995; NTSB Report, 1995; Hartley, Arnold, Smyth, \& Hansen, 1994). Research findings indicate that critical incidents occur more frequently when drivers have had, at most, 4-6 hours of sleep in the 24-hour period prior to the incident (Hanowski, Wierwille, Garness, \& Dingus, 1999). 
There are two types of drivers in the long-haul trucking industry: single drivers and team drivers. Single drivers operate alone, therefore sleeping in a stationary vehicle. Team drivers operate with a partner, therefore sleeping in a moving vehicle. The Federal Motor Carrier Safety

Administration (FMCSA) was interested in determining the effects, if any, of sleeper berth usage on driver fatigue.

While there has been extensive research in the area of long-haul truck driving and the effects of fatigue, this study is the first to obtain both objective and subjective measures of driving performance and drowsiness while the drivers were performing their normal daily tasks. Other studies have collected on-road data; however, none of these studies involved data collection in a naturalistic, unobtrusive manner on multiple-day trips. The data from this study will provide a more accurate understanding of truck drivers' actual work and sleep schedules.

\section{METHOD}

Long-haul truck drivers operated heavy trucks for a minimum of six days on their regularly assigned route. Drivers from three long-haul trucking companies were recruited for this project. One trucking company hauled dry goods and covered primarily the eastern coast of the US and Texas. The other two companies hauled refrigerated trailers coast to coast. VTTI's instrumented Class 8 tractors were loaned to the companies to haul the regularly scheduled loads.

\section{Data collection systems}

An automated data collection system was developed and installed in a 1997 L4 Volvo and a 1995 379 Peterbilt Class 8 heavy truck. This system allowed driving performance to be evaluated unobtrusively using cameras that recorded video surrounding a 'triggered-driving event.'

Four cameras were installed on the trucks. These four cameras recorded drivers' faces, the forward view, the left side rear-view, and the passenger side rear-view. The four views were recorded simultaneously through a quad-splitter so that trained data analysts could view all four images simultaneously (Figure 1).

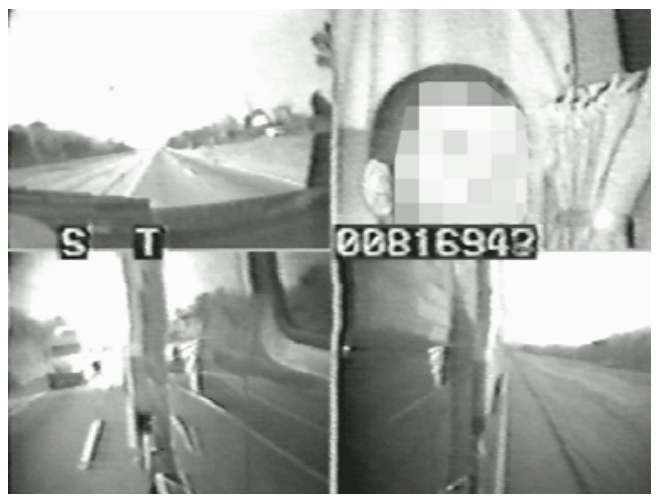

Figure 1. Four camera views as shown after being synchronized through a quad-splitter 
Twelve sensors were installed on the truck to monitor driving performance. These twelve sensors monitored steering, lateral and longitudinal acceleration, lane deviation, time-to-collision, side collision, and eyelid closure. When criteria values were exceeded for any driving performance sensor, objective measure of driver alertness, or subjective measure of alertness, the data collection system would save the recorded video for two minutes prior and one minute after the triggered-event occurred.

The data collection system operated automatically with minimal driver intervention. The triggerbased data collection system allowed the experimenters to obtain the driving performance and driver alertness data that would be important for analysis without recording hours of video that were not critical for the purposes of this study. For a more detailed description of the data collection system, the interested reader is referred to Dingus, Neale, Garness, Hanowski, Kiesler, Lee, et al. (2001).

\section{Driver Participants}

Thirty single drivers and 13 teams of drivers ( 56 total drivers) were recruited to participate in this study (seven females and 49 males). The mean age of the drivers was 42.6 years. Each driver drove a minimum of six continuous days with the typical run being seven to 10 working days. The schedules varied according to load assignment, truck maintenance, and requirements of the trucking company. All drivers volunteered and were paid for their participation in the study.

\section{Experimental Design}

This was a field study in which data from a large number of variables were collected to determine relationships between sleep quality, driver alertness, and driving performance. Data were collected from three general sources: the instrumented trucks, questionnaires, and data generated through video reduction.

Data from the instrumented trucks included driving-performance data collected via the sensors and video data collected via four inconspicuously mounted cameras. Analysts viewed the tapes, entered observer ratings of drowsiness, made determinations about the criticality, severity, and cause of the triggered event, and entered geographical information about the location of the triggered event. Questionnaire data included general demographic and driving experience information from the drivers, as well as daily workload information, sleep quality and quantity ratings, and logs of their activities.

\section{RESULTS}

The frequency of critical incident occurrence was significantly greater for single drivers than for team drivers by a factor of 4 to 1 , where single drivers were involved in 1,898 critical incidents and team drivers were involved in 564 critical incidents. A t-test indicated that the two groups were significantly different, $\mathrm{t}=13.16, \mathrm{p}<0.01$. Further analysis investigating the number of miles driven, age of drivers, or driving experience did not adequately explain the large differences in critical incident involvement. 
Observer ratings of drowsiness (ORD) were also compared to the number of critical incidents that occurred during four segments of time: morning (04:00 to 11:59), afternoon (12:00 to 17:59), evening (18:00 to 21:59), and night (22:00 to 03:59). The number of critical incidents per segment of day was divided by the number of hours driven during that segment of day to obtain a more accurate picture of the effects of time, traffic, meals, etc. An ANOVA was conducted to compare team (Figure 2) and single drivers' (Figure 3) performance for these segments of day. The main effect for segment of day was significant, $\mathrm{F}_{3,69}=4.00 ; \mathrm{p}<0.05$. Note that team drivers tended to exhibit critical incidents associated with extreme fatigue during the morning and night hours. Single drivers tended to show fewer extreme fatigue-related critical incidents during the morning hours, with gradually more critical incidents being attributed to the very drowsy categories during the evening and nighttime hours.

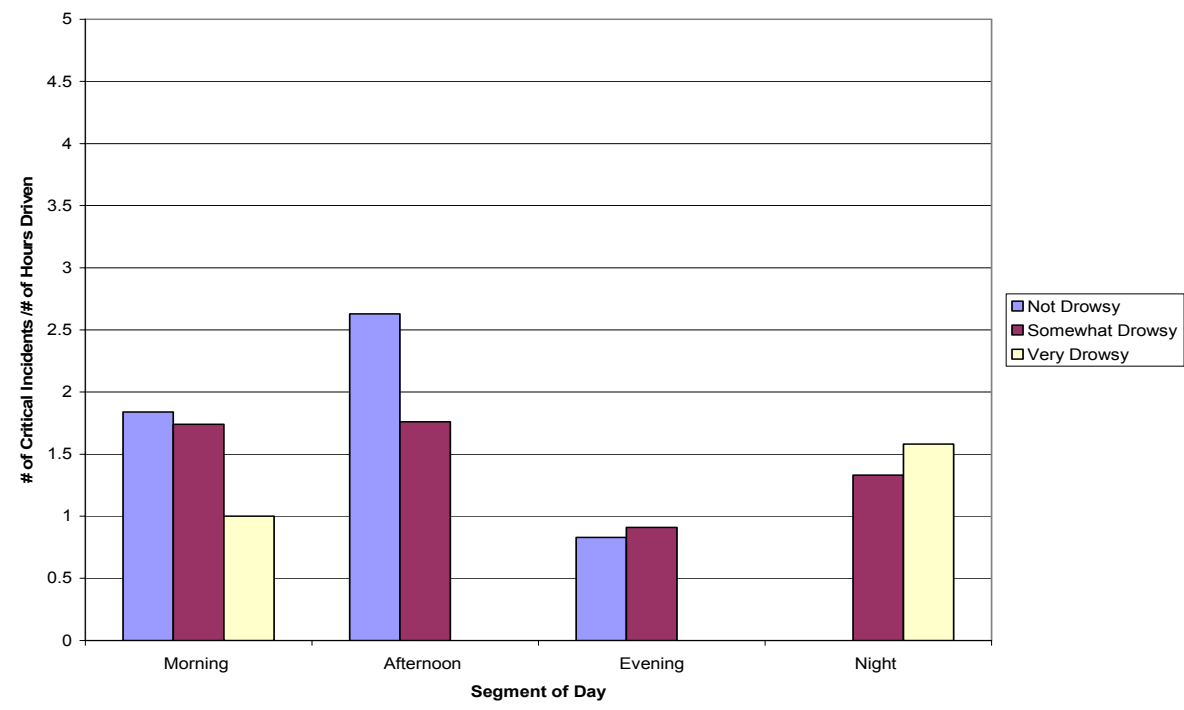

Figure 2. Ratio of incident occurrence to timed-triggers for a modified set of time of day and ORD categories, accounting for exposure for team drivers

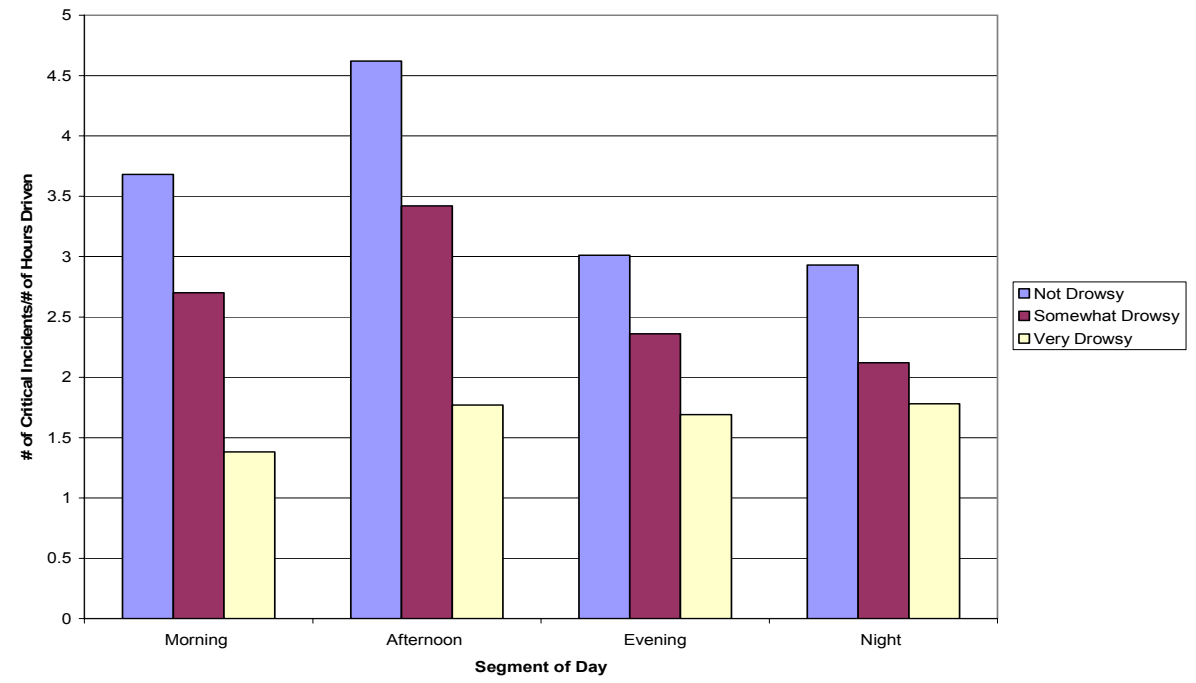

Figure 3. Ratio of incident occurrence to timed-triggers for a modified set of time of day and ORD categories, accounting for exposure for single drivers 


\section{CONCLUSIONS}

The results suggest that the team drivers in this study were better able to manage their fatigue and critical incident involvement than were single drivers. Possible explanations for these findings are that the team drivers were more likely to effectively trade-off driving duties with their partner prior to becoming extremely fatigued, whereas single drivers tended to drive when showing signs of fatigue. Note that single drivers were exhibiting signs of extreme fatigue during all hours of the day while team drivers only showed signs of fatigue during the nighttime and morning hours. This trend, along with generally lower numbers of incidents, is probably indicative of effectively trading-off driving duties. It is also possible that a "natural selection" may occur with voluntary team drivers, in that team drivers tend to drive with drivers they trust "with their life" (Neale, Robinson, Belz, Christian, \& Dingus, 1998). Voluntary team driving may be an effective method of training unsafe drivers or possibly "weeding out" unsafe drivers from the driving population.

\section{ACKNOWLEDGEMENTS}

The research reported here is funded by the Federal Motor Carrier Administration under contract number DTFH61-96-C-00068. The opinions expressed in this paper are those of the authors and do not necessarily represent official positions of any government agency or other individuals.

\section{REFERENCES}

Dingus, T., Neale, V., Garness, S., Hanowski, R., Keisler, A., Lee, S., Perez, M., Robinson, G., Belz, S., Casali, J., Pace-Schott, E., Stickgold, R., \& Hobson, J. (2001). Impact of Sleeper Berth Usage on Driver Fatigue. (Contract No. DTFH61-96-00068). Washington, DC: Federal Motor Carrier Safety Administration.

Hanowski, R. J., Wierwille, W. W., Garness, S. A., \& Dingus, T. A. (2000). Impact of Local Short Haul Operations on Driver Fatigue. (Contract No. DTFH61-96-C-00105). Washington, DC: Federal Motor Carrier Safety Administration.

Hartley, L. A., Arnold, P. K., Smyth, G. \& Hansen, J. (1994). Indicators of fatigue in truck drivers. Applied Ergonomics, 25, (3), pp. 143-156.

National Transportation Safety Board. (1995). Factors that affect fatigue in heavy truck accidents. Volume 1: Analysis. Safety Study NTSB/SS-95/01. Washington, DC.

Neale, V.L., Robinson, G. S., Belz, S.M., Christian, E.V., \& Dingus, T. A. (1998). Impact of sleeper berth usage on driver fatigue, Task 1: Analysis of trucker sleep quality. (Report No. DOT-MC-00-204). Washington, DC: Federal Motor Carrier Safety Administration.

Pack, A. L., Pack, A. M., Rodgman, E., Cucchiara, A., Dinges, D. F., \& Schwab, C. W. (1995). Characteristics of crashes attributed to the driver having fallen asleep. Accident Analysis \& Prevention, 27, No. 6, pp. 769-775. 